\title{
Chopper Controlled Resistors in VSC-HVDC Transmission for WPP with Full-scale Converters
}

\author{
S. K. Chaudhary, Student Member, IEEE, R. Teodorescu, Senior Member, IEEE, P. Rodriguez, \\ Member, IEEE, and P. C. Kjær Member, IEE
}

\begin{abstract}
Large and distant offshore wind power plants can be efficiently connected to the onshore power grid network using VSC-HVDC (Voltage Source Converter based HVDC) transmission. Chopper controlled resistors can be used to limit the DC line over-voltage when there is a fault on the onshore AC grid and power transfer to the grid is obstructed. Considering the development of full scale converter based wind turbine generators (WTG), use of unit rated chopper controlled resistors for each of the full scale AC-DC-AC converter system of the individual turbines has been proposed in place of the one on the HVDC line side. Both the cases have been simulated and their performances are found to be similar. Thus, it justifies that the chopper resistors in the full scale converters are sufficient to handle the low voltage fault ride through (LVRT) conditions.
\end{abstract}

Index Terms-Wind Power Plants, VSC-HVDC, Chopper controlled Resistors, DC Over-voltage, full scale converter, Wind turbine generators (WTG).

\section{INTRODUCTION}

$\mathrm{W}$ IND power plants (WPP) have come a long way from isolated wind turbines to clusters of large wind turbines of a few MW power sizes. Now WPP is regarded as a viable and competitive source of renewable energy. By the end of 2008 , total installed capacity of WPP reached above 120.8 GW in the world; out of this nearly $66 \mathrm{GW}$ has been installed in Europe, mostly onshore WPP's[1]. Due to scarcity of onshore sites, developments in offshore technologies and availability of a better aerodynamic profile, the trend in Europe is to develop large offshore WPP. By 2030, Europe expects to have $300 \mathrm{GW}$ of wind energy, of which $120 \mathrm{GW}$ is expected from Offshore WPP's[2].

A WPP comprises of a large number of wind turbine generators (WTG's) connected together at the collector bus. Each WTG has a wind turbine driving the generator, usually through a mechanical gearbox assembly. The generator may

This work was supported by a Vestas Power Program, a research collaboration of Vestas A/S and Aalborg University.

S. K. Chaudhary and R. Teodorescu are with the Department of Energy Technology, Aalborg University, Aalborg, 9220-Denmark. (e-mails: skc@iet.aau.dk and ret@iet.aau.dk ).

P. Rodriguez is with University of Catalonia, Barcelona, Spain. He is a visiting professor at the Department of Energy Technology, Aalborg University, Aalborg, 9220-Denmark. (e-mail: prodriguez@ee.upc.edu).

P. C. Kjær is with Vestas Wind Systems A/S, Denmark. (e-mail: pck@vestas.com) be directly connected squirrel cage induction machine running mostly around a fixed speed, or a doubly fed induction generator which can allow $25-30 \%$ speed variation.

While variable speed induction generators provide a flexible coupling to the grid, synchronous machine has a stiff coupling to the grid as it can run only at synchronous speed. A small deviation around the synchronous speed produces a corrective torque on the machine so as to return to the synchronous speed. Such a stiff coupling between the generator and the grid is undesirable in wind turbine generator as the transient torques produced in the shaft causes significant mechanical stress on the gears [3]. Full scale converters can decouple the synchronous machine speed from the grid frequency and thus provide for flexible operation over a wide range of speed. The present paper assumes synchronous generators with full converters, though it is equally applicable for induction generators using full power rated converters.

Fig. 1 shows a single line diagram of a WPP comprising of WTG with full scale converters (FSC). Output voltage of the WTG's with full scale converters are stepped up to connect to the collector bus. The collector bus voltage is further stepped up and then connected to the onshore AC grid network using high voltage cables. Due to cable-charging and subsequent reactive power management issues associated with High Voltage AC (HVAC) cable transmission, High Voltage DC (HVDC) transmission is favorable, especially for long distance cable transmission [4]. Developments in the last decade in voltage source converter (VSC) technology has led to the evolution of VSC based HVDC (VSC-HVDC) transmission system. Such a VSC-HVDC transmission is capable of 4-quadrant operation enabling full control of both the active and reactive powers at both ends of the DC transmission, independently of each other.

In Fig. 1, synchronous generators driven by wind turbines operate at variable frequencies corresponding to their speed of operation. Each of them is coupled to a common collector bus operating at controlled frequency of $50 \mathrm{~Hz}(60 \mathrm{~Hz}$ or other frequency of operation is equally feasible) through a full scale AC-DC-AC converter (FSC). The collector bus voltage is stepped up and then rectified to HVDC for transmission to the onshore grid. Onshore the HVDC is inverted back to HVAC and then connected to the $\mathrm{AC}$ grid through interconnecting transformers. Tuned filters are used at both terminals of VSC- 


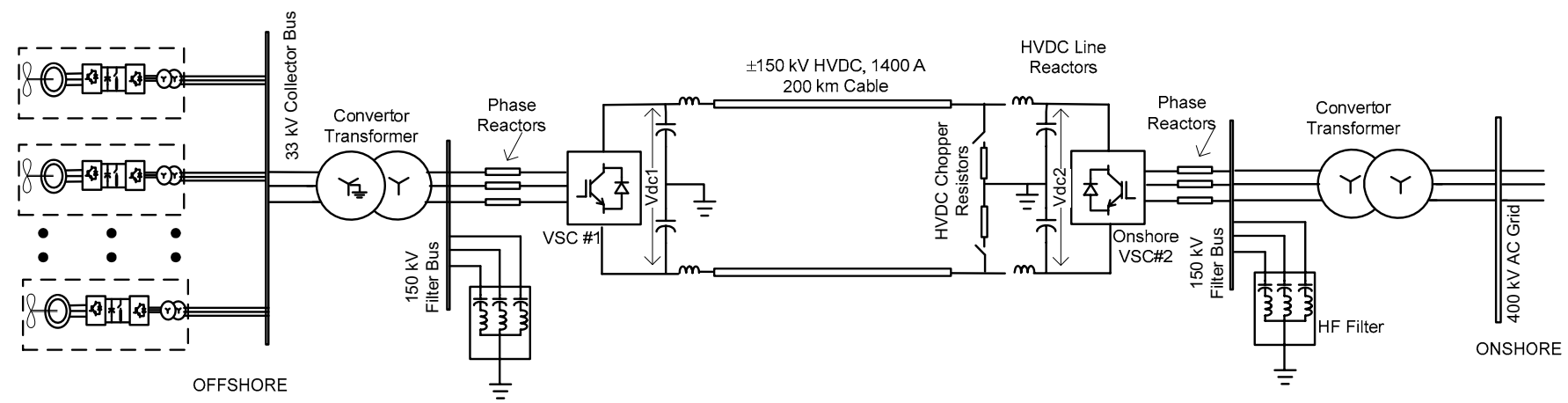

Fig. 1 VSC-HVDC Connection for Wind Power Plant comprising of Wind Turbines with Full Scale Converters

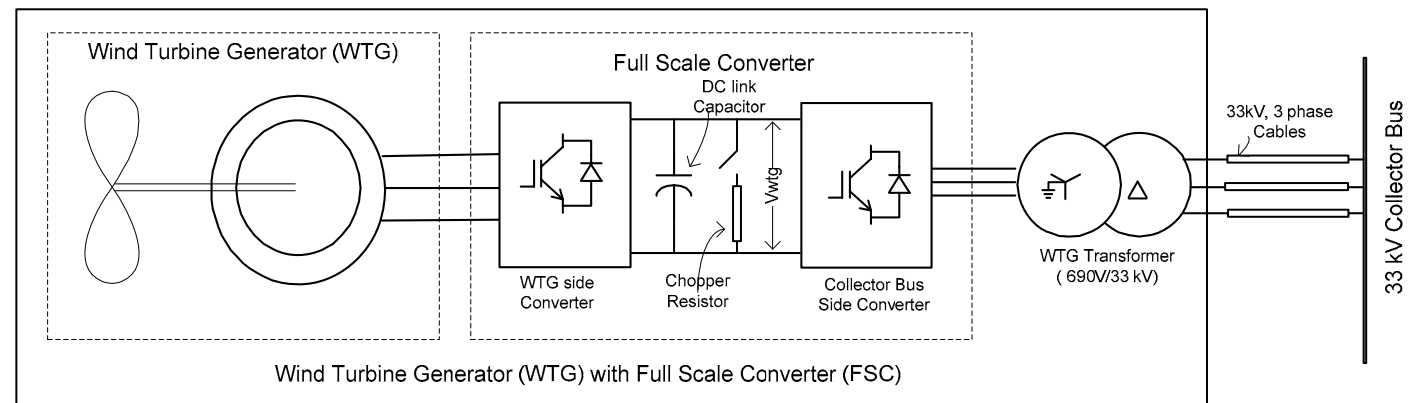

Fig. 2 Wind Turbine Generator with Full Scale AC-DC-AC Converter, Chopper resistor in the DC link and its transformer

HVDC to filter out the high frequency harmonics. Different control strategies can be adopted for the HVDC transmission system. This paper refers to a specific case, in which the offshore VSC controls the voltage magnitude and frequency of the offshore grid voltage. Power control strategies remain with the WPP-controllers. The onshore VSC regulates the DC link voltage, such that under normal operating conditions, the power injected into the dc grid is transferred to the onshore AC grid and power balance is maintained [5].

However, when there is a fault on the onshore ac grid, the AC grid voltage at the point of common coupling (PCC) dips, thereby reducing the power transfer capability from the onshore VSC-HVDC terminal. On the other hand, power generated by the WTG's cannot be ramped down instantaneously. The excess power gets accumulated in the VSC-HVDC system capacitance, thereby, leading to DC overvoltage. Chopper controlled resistors are used to dissipate the excess power and thus limit DC voltage rise within safe levels, while the WTG's are signaled to reduce their generation as quickly as possible [6,7]. Chopper controlled resistors have been used in HVDC Nord E.ON 1 to prevent DC overvoltages by temporarily dissipating the excess power [8].

Chopper controlled resistors have been used as braking resistors to dissipate the braking energy in variable frequency drives [9]. Similar scheme is used in the FSC in WTG to check the DC link over-voltages in their DC link [9]. In this paper the performance of the chopper resistor in the FSC is compared with the performance of chopper resistor in the HVDC system with respect to controlling the HVDC system over-voltage during low voltage faults in the onshore grid.

Section II describes the origin of over-voltage in the HVDC system during onshore grid faults and the role of chopper resistors in controlling it within safe limits. In section III, the PSCAD model of the WPP-HVDC system is briefly explained. Simulation of the two cases with different voltage dip levels and the observed results are discussed in section IV and then finally it is concluded in section V.

\section{DC OVER-VOLTAGE AND ITS CONTROL}

Onshore grid fault close to the VSC-HVDC terminal is may dip the AC grid voltage to very low levels, thereby affecting power transfer from the HVDC converters to the grid. E.On Grid Code requires that the WPP remain connected till the grid voltage at the PCC drops down to $0 \%$ of the nominal levels for periods lasting as long as $150 \mathrm{~ms}$, and inject reactive current to assist in the system recovery [11]. As the fault is cleared and voltage starts building up, the WPP has to ramp up active power supply. In VSC-HVDC transmission, chopper controlled resistors are used to provide low voltage ride through capability.

\section{A. Mathematical Analysis for the Overvoltage}

Power transfer capability from the Grid Side VSC to the grid is given by the formula,

$$
P_{c g}=\frac{V_{c}^{*} V_{g}}{X_{p h}} \sin \left(\delta_{c}-\delta_{g}\right)
$$

Where,

$P_{c g}$ - Power transfer from the converter to the grid

$V_{c} \angle \delta_{c}-C o n v e r t e r$ terminal voltage (Magnitude and Phase of the fundamental component)

$V_{g} \angle \delta_{g}$-Grid terminal voltage (Magnitude and Phase at the filter bus),

$X_{p h}$-Reactance of the phase reactor 
The resistance, $R_{p h}$, of the phase reactor is negligible in comparison to the reactance and hence neglected for simplicity.

From (1), if $V_{g}$ drops to 0 , active power cannot be transferred to the grid. The converter can, however, supply the reactive current corresponding to its current ratings. Under such circumstances, and as long as the WPP power generation $\left(\mathrm{P}_{\mathrm{wpp}}\right)$ cannot be ramped down, the WPP side VSC continues injecting the collected power into the HVDC line and the capacitors, thereby resulting in DC over-voltages, as given by Eq. 2.

$$
V_{d c}=\sqrt{\frac{2}{C_{e q}} \int\left(P_{w p p}-P_{c g}\right) \cdot d t}
$$

Where, $C_{e q}$ is the equivalent capacitance of the HVDC line and the DC capacitors.

\section{B. Chopper Controlled Resistors}

The DC over-voltage can be controlled within safe limit if the excess power is dissipated by some means, like chopper controlled resistors. Total equivalent size of such resistor can be estimated by,

$$
R_{\text {chop }}=\frac{V_{\text {rated }}^{2}}{P_{\text {rated }}}
$$

If the dc over-voltage can be limited to $5 \%$ of the rating, the short time current rating of the chopper-resistor system has to be,

$$
I_{\text {chop }}=\frac{1.05 \cdot V_{\text {rated }}}{R_{\text {chop }}}=\frac{1.05 \cdot P_{\text {rated }}}{V_{\text {rated }}}=1.05 \cdot I_{\text {rated }}
$$

In other words, the chopper-resistor system has to be rated for $5 \%$ over-current, at least for the short time, and $5 \%$ overvoltage.

\section{Chopper Controlled Resistors in Full Scale Converters}

When every WTG is equipped with a FSC, the chopper controlled resistors can be placed on the DC links of the WTG-FSC's. During the periods while DC over-voltage persists, the WPP side VSC-HVDC controller may be active to bring down the HVDC voltage. Eventually, it will reduce or block power injection into the HVDC system. Then, the WTG-FSC will see power unbalance as power injected by the WTG does not get transferred to the VSC-HVDC. Consequently, there is overvoltage in its DC link. Chopper controlled resistors can be used at this stage to avoid such overvoltage build up. Since the WTG-FSC system is rated for the turbine power and voltage rating, the chopper-resistor system can be of the same rating and thus smaller in size and capacity. In this way, the chopper-resistor in the HVDC system can be replaced by smaller chopper-resistor units in each of the WTG-FSC.

$$
\begin{aligned}
R_{W T G, \text { chop }} & =\frac{V_{W T G, \text { rated }}^{2}}{P_{W T G, \text { rated }}} \\
I_{W T G, \text { chop }} & =1.05 \cdot I_{W T G, \text { rated }}
\end{aligned}
$$

\section{SIMPLIFIED MODEL OF WPP WITH VSC-HVDC CONNECTION}

Fig. 3 shows a simplified model of the WPP comprising of WTG's with FSC's, and connected to the grid by VSC-HVDC connection. The VSCs of the HVDC have been modeled in terms of current and voltage sources. The converter AC terminals are represented as 3-phase AC voltage sources, the voltage magnitude being decided by the control algorithm adopted. The DC side has a current source determined on the basis of power exchanged with the AC terminals.

In the present model, the grid side VSC controls the HVDC transmission voltage around the specified reference value. In order to achieve this, DC voltage control loop in the onshore VSC-HVDC controller determines the power to be evacuated to the grid and sets the d-axis current reference. The q-axis current reference is set from the desired reactive power exchange level. The reactive power exchange may be commanded or estimated for AC voltage control at the PCC. The inner current control loops estimates the voltage magnitude in $\mathrm{d}$ and $\mathrm{q}$ axes so as to attain the reference current flows through the phase reactors against the grid voltage at the point of common coupling. Using phase locked loop (PLL) to obtain the instantaneous angle of the voltage vector and then applying Park's transformation, the instantaneous three phase voltage can be synthesized. Since average value models have been used for representing the VSC's in terms of current and voltage sources, switching harmonics will not appear and the filters have been ignored in this study. On the WPP side, the VSC AC terminal voltages are set at desired AC voltage and frequency. The WTG-FSC's are modeled in a similar way.

Each WTG, shown in Fig 4, has been treated as a constant power source.. Reactive power of the WTG does not affect the net power flow in the DC link of full scale converter; and it has been ignored. The WTG's have been modeled as three phase current sources, driving current against the measured 3phase voltage at the point of connection. The magnitude of the current is decided by the specified active and reactive power output and the positive sequence component of the measured voltage at the interface. The output $\mathrm{AC}$ terminals on the collector bus side of the full scale converters have been modeled such that excess power from the DC link is injected into the collector bus and an equivalent current is drawn from the DC link. Thus, DC link voltage control is achieved.

The current sources representing the AC side of the WTGFSC are computed at $33 \mathrm{kV}$ level. The transformer is simply represented by its series impedance. The $33 \mathrm{kV}$ cable connecting the WTG transformer to the collector bus has been modeled.

The chopper resistors and their switching during DC overvoltages have been modeled as equivalent average current sources for the dissipation of excess power. The value of current dissipated depends upon the level of over-voltage.

The grid has been modeled as a voltage source behind impedance. The grid impedance is estimated on the basis of short circuit level and impedance angle of the grid. 


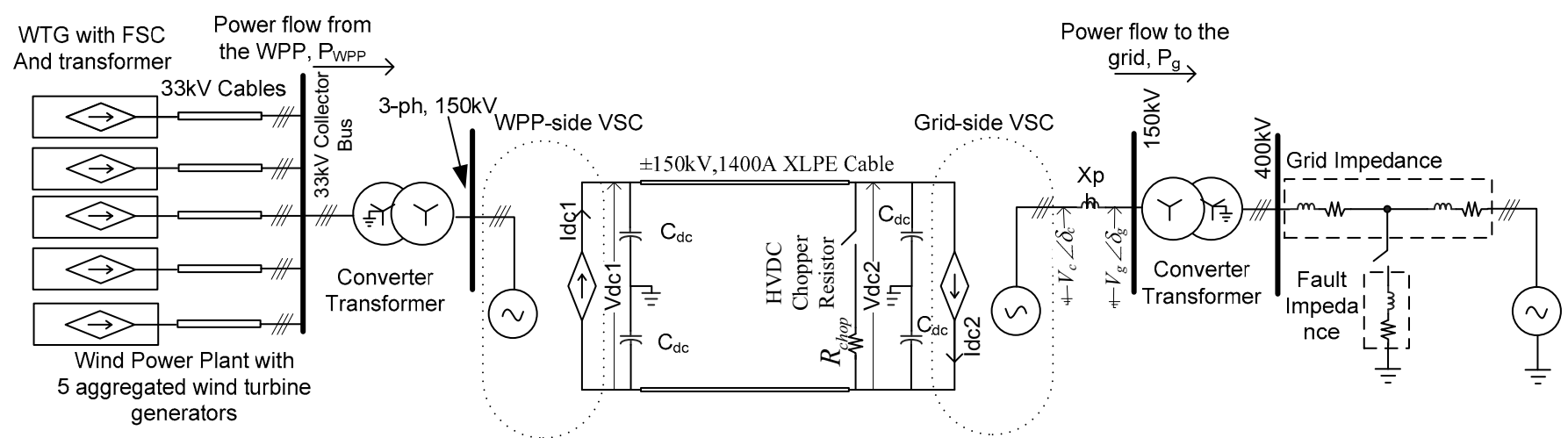

Fig. 3 Simulation Model of WPP-HVDC-grid system

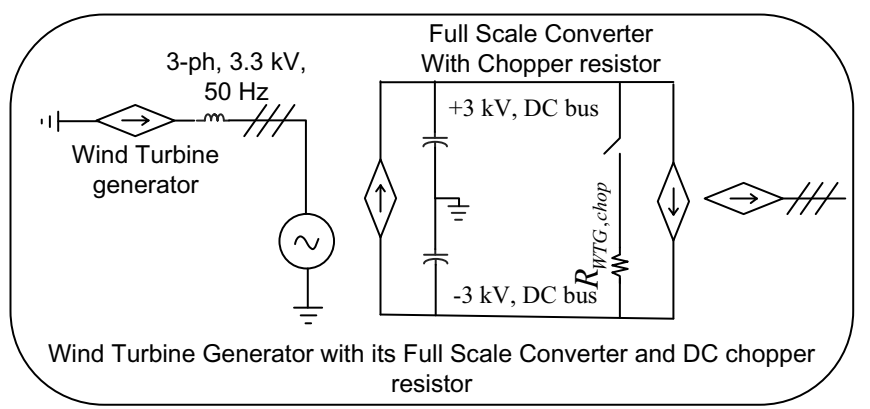

Fig. 4 Model of a Wind Turbine Generator with Full Scale Converter

\section{Simulation OF THE WPP WITH HVDC}

A $400 \mathrm{MW}$ WPP with $80 \mathrm{x} 5 \mathrm{MW}$ WTG's connected to the onshore AC grid through VSC-HVDC transmission has been modeled in PSCAD as 5 aggregated WTG of $80 \mathrm{MW}$ size and simulated to study the low voltage fault ride through performance of the WPP-HVDC system. The WTG's are assumed to continue operating at constant power level; no reduction in generation is applied during fault. The system parameters are given in Table 2 in the Appendix.

Two sets of cases have been studied and compared. In the first set of cases the chopper resistors are placed in the HVDC-transmission system. In the second set of cases the chopper resistors are installed in the full scale converters of the wind turbine generators.

An additional case has been studied to study the DC overvoltage when the fault is at the collector bus.

\section{A. Chopper Resistors on HVDC Transmission Terminal}

As shown in Fig. 2, chopper resistors are placed on the grid side VSC terminal of the HVDC transmission system. DC over-voltages in the HVDC lines and the full scale converters have been studied when the ac voltage at the $150 \mathrm{kV}$ bus of the converter transformer dips to $19 \mathrm{kV}, 42 \mathrm{kV}, 80 \mathrm{kV}$ and $118 \mathrm{kV}$ for $150 \mathrm{~ms}$ duration. These voltage levels are arrived at when voltage dips to $10 \%, 25 \%, 50 \%$ and $75 \%$ of nominal levels are simulated by dividing the grid impedance into two parts and connecting the fault impedance between them.

Fig. 5 shows the power flowing from the collector bus and the reduced power transfer to the grid when the voltage at the $150 \mathrm{kV}$ bus dips to $42 \mathrm{kV}$. The resultant over-voltage in the HVDC system and chopper resistor current is shown in Fig. 6.

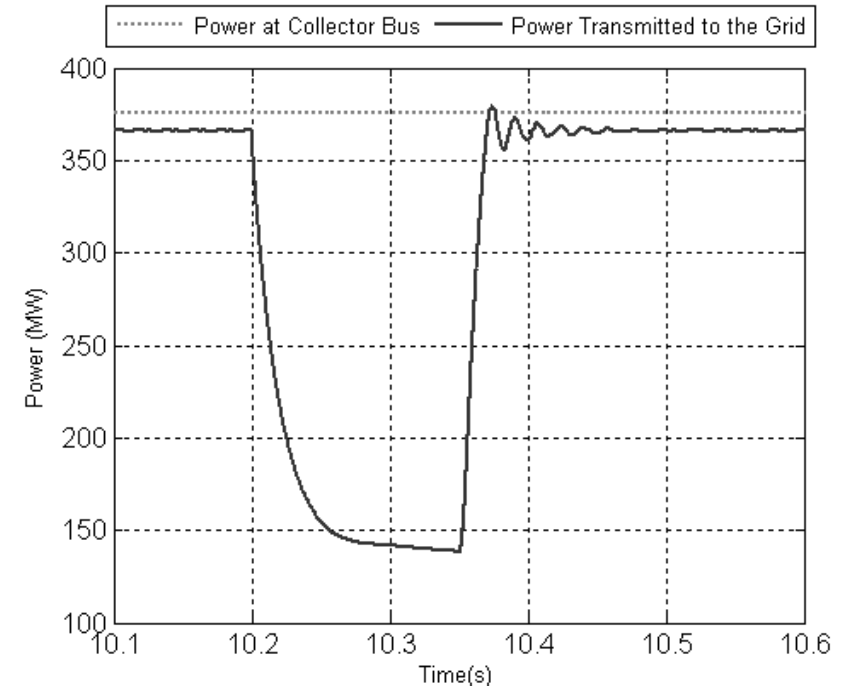

Fig. 5 Power at Collector Bus and Power Transmitted to the Grid when the $\mathrm{PCC}$ voltage dips to $42 \mathrm{kV}$ in Case A.
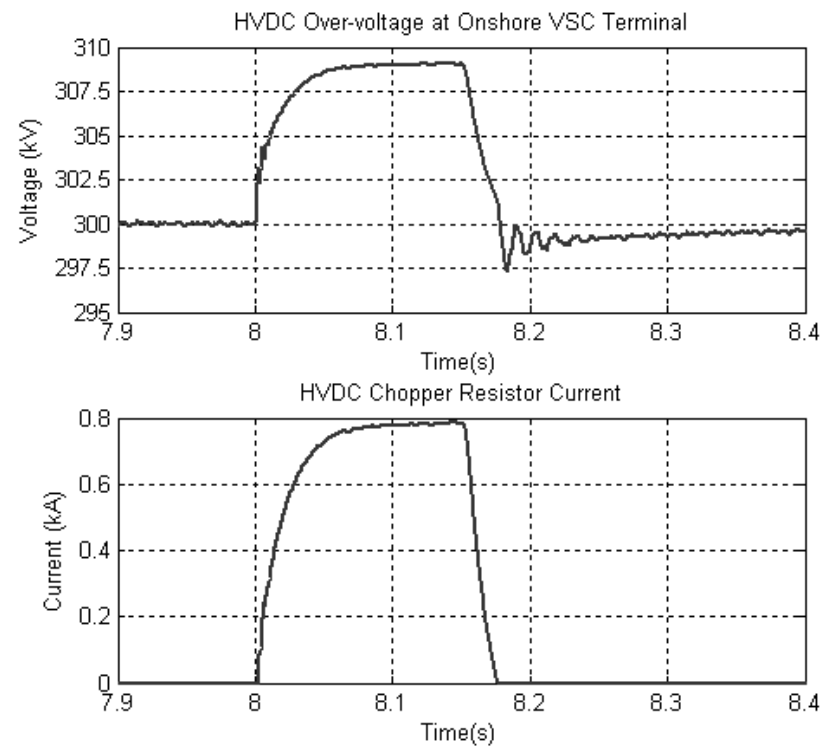

Fig. 6 HVDC Over-voltage and chopper resistor current when the PCC voltage dips to $42 \mathrm{kV}$ in Case A

HVDC voltage at the grid side VSC rises to $309 \mathrm{kV}$ while the power flow into the grid drops to $128 \mathrm{MW}$. The peak current through the chopper resistor is $0.8 \mathrm{kA}$. Table 1 summarizes the power flow, observed DC over-voltage and peak current through the chopper resistor for the different voltage dips simulated. 
TABLE 1 DC OVERVOLTAGE FOR IN CASES A AND B DURING VOLTAGE DIPS OF DIFFERENT LEVELS AT THE PCC

\begin{tabular}{|c|c|c|c|c|c|c|}
\hline \multirow{2}{*}{$\begin{array}{c}\text { 3-ph rms } \\
\text { voltage } \\
\text { at } \mathrm{PCC} \\
(\mathrm{kV})\end{array}$} & \multirow{2}{*}{$\begin{array}{c}\text { Power } \\
\text { Evacuatio } \\
\mathrm{n} \text { to the } \\
\text { Grid (MW) }\end{array}$} & \multicolumn{3}{|c|}{$\begin{array}{l}\text { Maximum DC Over-voltage } \\
\text { During Fault }(k \vee, D C)\end{array}$} & \multicolumn{2}{|c|}{$\begin{array}{c}\text { Chopper Resistor } \\
\text { Current }\end{array}$} \\
\hline & & $\begin{array}{c}\text { Case A : } \\
\text { o/ in } V \mathrm{SC}- \\
\text { HVDC }\end{array}$ & $\begin{array}{c}\text { Case B : } \\
\text { of in } \\
\text { VSC- } \\
\text { HVDC }\end{array}$ & $\begin{array}{c}\text { Case B : } \\
\text { oh in DC } \\
\text { lionk of } \\
\text { FSC }\end{array}$ & $\begin{array}{c}\text { Case A: } \\
\text { (in Amp } \\
@ 300 k V \\
\text { DC) }\end{array}$ & $\begin{array}{c}\text { Case B : } \\
\text { (in Amp } \\
@ 6 \mathrm{kV} \\
\text { DC) }\end{array}$ \\
\hline 19 & 58 & 311 & 312 & 6.23 & 1006 & 664 \\
\hline 42 & 128 & 309 & 310 & 6.19 & 787 & 522 \\
\hline 80 & 243 & 306 & 307 & 6.12 & 419 & 282 \\
\hline 118 & 360 & 302 & 304 & 6.03 & 37 & 23 \\
\hline
\end{tabular}

\section{B. Chopper Resistors in the DC links of FSC-WTGs}

Chopper resistors are placed on the DC link of the WTGFSC's, as shown in Fig 1. The chopper resistor in the HVDC system is deactivated. When the offshore terminal DC voltage exceeds the estimated offshore DC voltage by a certain amount, say $1 \%$ (in this case), the WPP side VSC generates a 'reduction factor (RF)' for the reduction in the input power. It is applied to the WTG-FSC to reduce the output power. In practice, this might be attained through a communication link or it may be signaled through a reduction of collector bus voltage and/or rise in frequency.

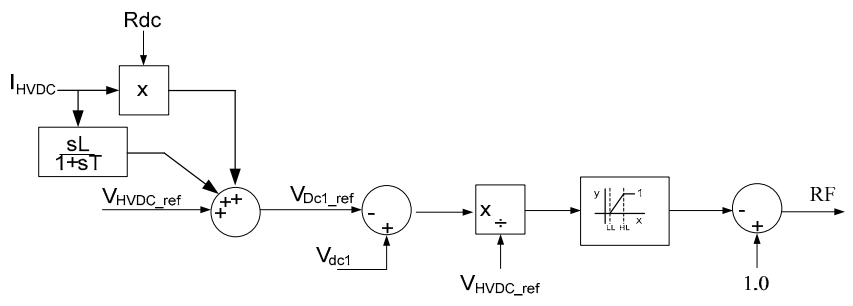

Fig. 7 Generation of Reduction Factor for Active Power input to the WPP-side VSC

Fig. 7 shows a block diagram for generating the reduction factor (RF). The nominal HVDC voltage at the offshore VSC terminal is estimated by adding the voltage drop in the HVDC cable resistance and inductance to the VSC-HVDC reference voltage specified at the grid side VSC and then compared with the measured offshore HVDC voltage. The over-voltage above certain threshold ( $\mathrm{LL}=1 \%$ ) is thus sensed and then used to determine RF. A linear function has been shown; though any other function might be used depending upon specific cases. Further the power input reduction has been assumed to fall down to 0 when the over-voltage hits or exceeds the upper threshold $(\mathrm{HL}=5 \%)$. $\mathrm{RF}$ may be allowed to drop down to negative values so as to facilitate the quick reduction of overvoltage.

For the simulated case when the voltage dips to $42 \mathrm{kV}$ level at the $150 \mathrm{kv}$ terminal of the converter transformer, Fig. 8 shows that the power input to the HVDC system is reduced progressively as the HVDC system voltage rises to $312 \mathrm{kV}$ (observed at the grid side VSC). Fig. 9 shows the chopper resistor peak current rising to $522 \mathrm{~A}$ at the DC-link voltage of $6.19 \mathrm{kV}$. Power transferred to the grid, DC over-voltage at the onshore terminal of VSC-HVDC, and the current dissipated in the chopper resistor HVDC for other voltage dip levels are compared with those of case ' $A$ ' in Table 1 . The overvoltage observed in the DC link of WTG-FSC is given as well.

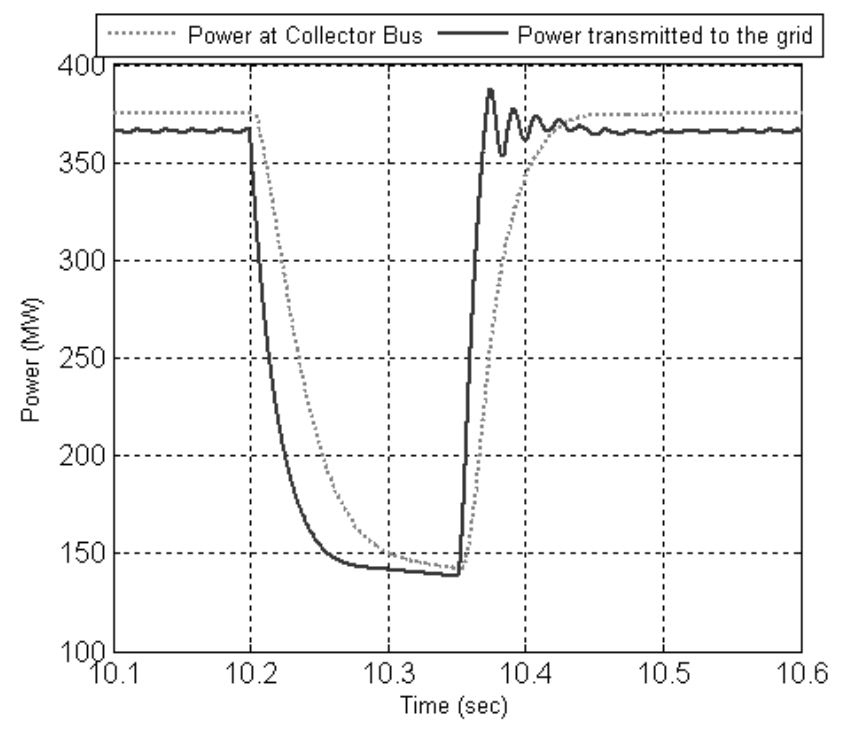

Fig. 8 Power at Collector Bus and Power Transmitted to the Grid when the PCC voltage dips to $42 \mathrm{kV}$ in Case B.

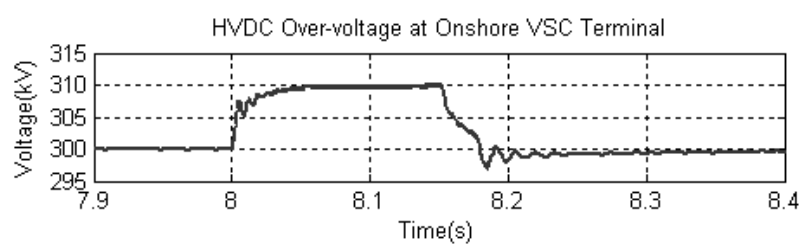

DC Over-voltage on the DC-Link of WTG-FSC
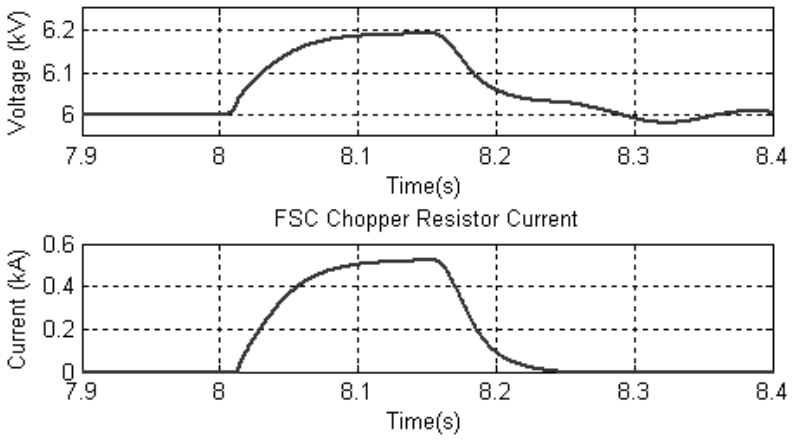

Fig. 9 : Over-voltages in the HVDC system, the WTG-FSC DC link and the FSC chopper resistor current when the PCC voltage dips to $42 \mathrm{kV}$ in Case B.

\section{Fault in the Collector Bus: Overvoltage on the DC-link of the FSC's}

When there is a fault in the offshore grid, say at the collector bus, the HVDC transmission system will not experience any overvoltage phenomena. Rather, it will experience sudden over-currents in the converters and go into protection mode by disconnection or switching into current limited operation mode; thereby interrupting the power flow into the HVDC system. Depending upon whether the WPP side VSC-HVDC converter remains connected or not, the collector bus side VSC of the full scale converter might have to be disconnected in absence of any synchronizing voltage or it might be operating in a current limited mode at a very low AC terminal voltage due to the fault. In both the situations, the WTG-FSC will see a sudden reduction of power output, 
whereas the input remains constant. Consequently, the excess power in the DC link will lead to over-voltage in the DC link.
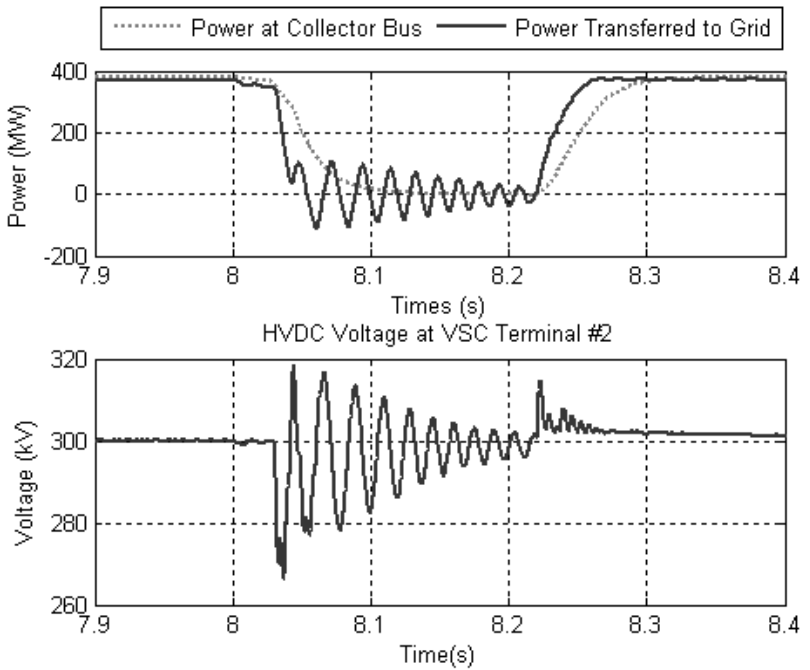

Fig. 10 i)Power at the Collector bus and the power transmitted to the grid ii) HVDC Voltage fluctuation
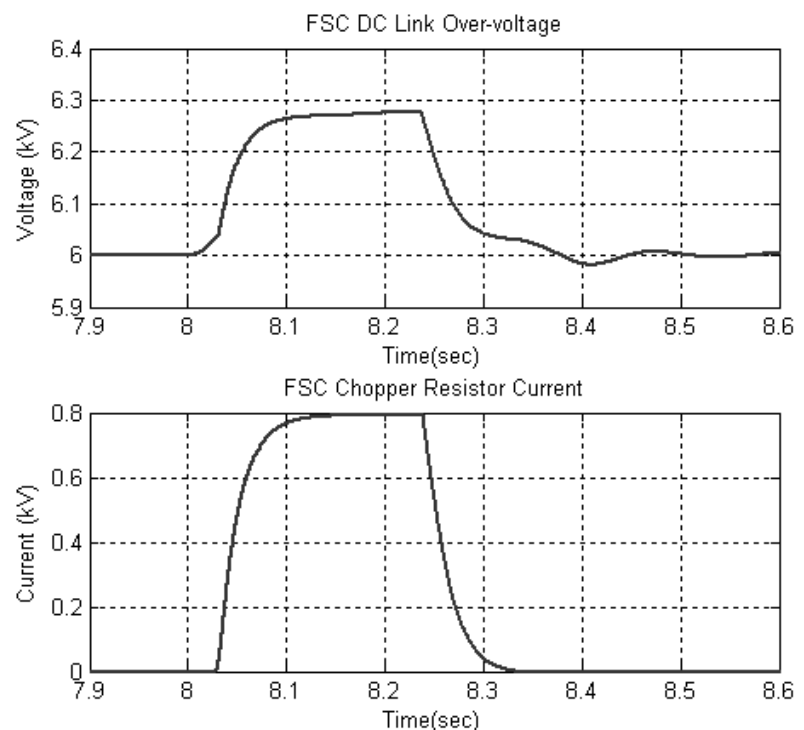

Fig. 11 i) Chopper Resistor Current in the DC link of the Full Scale Converter and ii) DC link over-voltage of the Full Scale converter during Voltage dip to $42 \mathrm{kV}$ at the Collector Bus

Fig. 10 shows the power flow to the $\mathrm{AC}$ grid and the HVDC voltage when a fault is simulated on the collector bus. Fig 11 shows that current dissipation in the chopper resistors and the over-voltage in the DC-link of WTG-FSC is checked within slimits. On the other hand, as shown in Fig. 12, there is no means to dissipate the excess energy and the DC link attains high over-voltage when there is not any chopper resistor in the DC link of WTG-FSC.

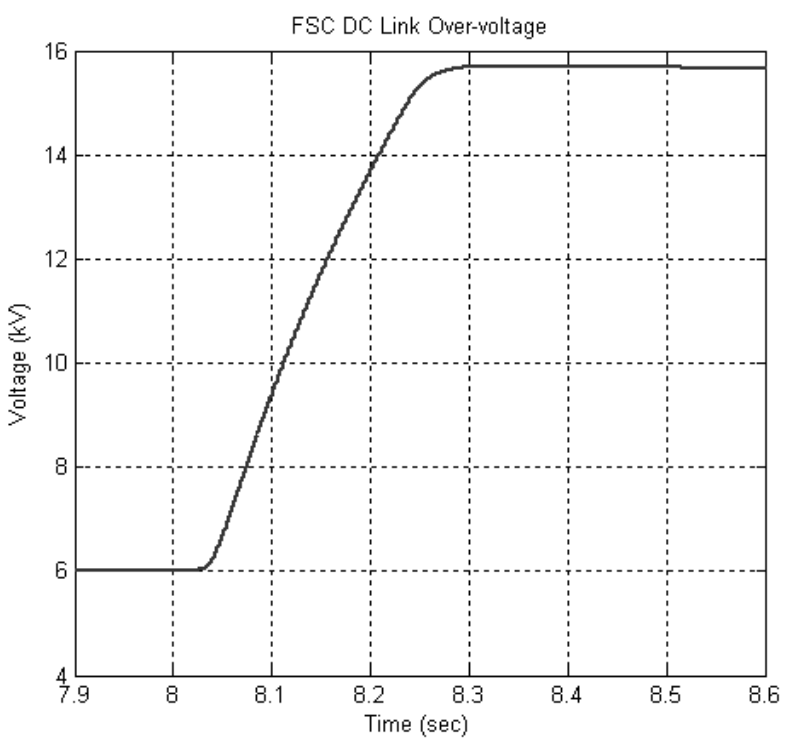

Fig. 12 DC link over-voltage in the Full Scale converter during voltage dip to $42 \mathrm{kV}$ at the Collector Bus in absence of the chopper resistor.

\section{CONCLUSIONS}

Similar levels of over-voltages in HVDC system have been observed in the two sets of simulated cases when the chopper resistors are placed in the HVDC system and when they are placed in the DC links of the full scale converters. Through this simplified simulation results, the two methods appear to perform in a similar way to check the HVDC system overvoltage.

However, using the chopper resistors in the DC link of the full-scale converters has merit as the resistor size and ratings is greatly reduced when compared to a large resistor bank required when it is placed on the HVDC line. Putting the chopper controlled resistors in the DC link of full scale converters will be an attractive option as these will have to face a lower DC voltage and power ratings. Further, the chopper resistor on each of the full-scale converter provides them DC-link over voltage protection against faults between the full scale converter and the HVDC converter, for example a fault on the collector bus.

Therefore the WTG-FSC's should be equipped with the chopper controlled resistors while the chopper resistor in the HVDC may be eliminated.

The study assumes that the WPP does not ramp down the power generation. However, modern WTG's are capable of cutting down power generation by pitch regulation. Though it is a slow control when compared to electrical control systems, it would still help in optimizing the chopper resistors. 


\section{APPENDIX}

Table 2 : System Parameters used in the simulation

\begin{tabular}{|c|c|c|}
\hline \multicolumn{3}{|l|}{ Onshore Grid } \\
\hline \begin{tabular}{l|l|}
1 & Base MVA \\
\end{tabular} & 500 & MVA \\
\hline \begin{tabular}{l|l|}
2 & Base voltage (rms, line-line) \\
\end{tabular} & 400 & $\mathrm{kV}$ \\
\hline \begin{tabular}{|l|l|}
3 & Shor Circuit Capacity \\
\end{tabular} & 25 & pu \\
\hline 4 Grid Impedance Angle & 80 & degree \\
\hline \multicolumn{3}{|l|}{ Converter Transformers (Onshore) } \\
\hline Size & 500 & MVA \\
\hline Voltage Ratio (for onshore) & $400 / 150$ & $\mathrm{kV}$ \\
\hline Voltage Ratio (for offshore) & $150 / 33$ & $\mathrm{kV}$ \\
\hline Leakage Reactance & 0.07 & pu \\
\hline Cu-loss & 0.01 & pu \\
\hline Fe-loss & 0.01 & pu \\
\hline \multicolumn{3}{|l|}{ Phase reactors } \\
\hline \begin{tabular}{l|l}
5 & Inductance \\
\end{tabular} & 17 & $\mathrm{mH}$ \\
\hline \begin{tabular}{l|l}
6 & resistance \\
\end{tabular} & 10 & mOhm \\
\hline \multicolumn{3}{|l|}{ HVDC System } \\
\hline \begin{tabular}{l|l} 
Pole to pole DC boltage \\
\end{tabular} & 300 & kV DC \\
\hline Power rating & 400 & MW \\
\hline \multicolumn{3}{|l|}{ HVDC Cable } \\
\hline \begin{tabular}{l|l} 
Cable length \\
\end{tabular} & 200 & $\mathrm{~km}$ \\
\hline resistance & 2.797 & Ohm \\
\hline Inductance & 22.31 & $\mathrm{mH}$ \\
\hline Shunt Capacitance & 28.15 & uF \\
\hline DC capacitors (at VSC terminal) & 35.5 & uF \\
\hline \multicolumn{3}{|l|}{ Offshore WTG Cables } \\
\hline \begin{tabular}{l|l} 
Conductor Cross Section \\
\end{tabular} & 150 & sq. $\mathrm{mm}$ \\
\hline Length & 2 & $\mathrm{~km}$ \\
\hline resistance & 0.248 & Ohm \\
\hline Inductance & 0.72 & $\mathrm{mH}$ \\
\hline Shunt Capacitance & 0.4 & uF \\
\hline WTG-FSC DC Voltage & & $\mathrm{kV}$ \\
\hline
\end{tabular}

\section{ACKNOWLEDGMENT}

This work is a part of the research being carried out for the Vestas Power program. The program is funded by Vestas Wind Systems A/S, Denmark and Aalborg University, Denmark. The authors gratefully acknowledge the financial and technical support of Vestas Wind Systems A/S.

\section{REFERENCES}

[1] Global wind report 2008. Global Wind Energy Council (GWEC), Available:

http://www.gwec.net/fileadmin/documents/Publications/Report_2008/Global_ Wind 2008_Report.pdf

[2] S. K. Chaudhary, R. Teodorescu and P. Rodriguez, "Wind Farm Grid Integration Using VSC Based HVDC Transmission - An Overview," IEnergy 2030 Conference, 2008. ENERGY 2008. IEEE, pp. 1-7, 2008.

[3] J. Machowski, J. W. Bialek and J. R. Bumby, Power System Dynamics : Stability and Control. ,2nd ed.Chichester, U.K.: Wiley, 2008, pp. 629.

[4] T. Ackermann, Wind Power in Power Systems; Wind Power in Power Systems. ,Elektronisk udgave ed.Chichester: John Wiley, 2005, pp. xlvii, 691.
[5] C. Feltes and I. Erlich, "Variable Frequency Operation of DFIG based Wind Farms connected to the Grid through VSC-HVDC Link," Power Engineering Society General Meeting, 2007. IEEE, pp. 1-7, 2007.

[6] P. Sandeberg and L. Stendius, "Large scale offshore wind power energy evacuation by hvdc light ${ }^{\mathbb{B}}$," presented at European Wind Energy Conference \& Exhibition 2008. Available: http://library.abb.com/global/scot/scot221.nsf/ veritydisplay/ba91daab7c7f5f8dc125747a0051a5dc/\$File/Large $\% 20$ scale $\% 20$ Offshore $\% 20$ Wind $\% 20$ Power $\% 20$ Energy $\% 20$ evacuation $\% 20$ by $\% 20 \mathrm{HVDC} \%$ 20Light.pdf

[7] A. A. Meer, R. L. Hendriks and W. L. Kling, "A survey of fast power reduction methods for VSC connected wind power plants consisting of different turbine types," presented at $2^{\text {nd }}$ EPE Wind Energy Chapter Seminar, KTH, Stockholm, 23-24 April 2009.

[8] ABB review 4/2008: The future is now (on the offshore HVDC light link NordE.ON 1, germany). Available: http://www.abb.com/industries/ap/ db0003db004333/9c43e75526ca8b96c12574a900338059.aspx

[9] N. Mohan, T. M. Undeland and W. P. Robbins, Power Electronics Converters, Applications, and Design; Power Electronics Converters, Applications, and Design. ,3rd ed.Hoboken, NJ: John Wiley \& Sons, 2003.

[10] J. Conroy and R. Watson, "Aggregate modelling of wind farms containing full-converter wind turbine generators with permanent magnet synchronous machines: transient stability studies," Renewable Power Generation, IET, vol. 3, pp. 39-52, 2009

[11] "Grid Code for High and Extra High Voltage," E.ON Netz GmbH Bayreuth,April 1, 2006..

\section{BIOGRAPHIES}

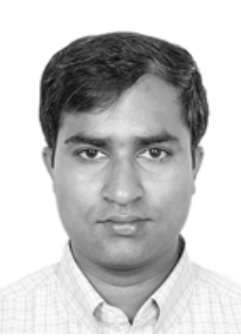

Sanjay Kumar Chaudhary(S'02-M'05-SM'08) was born in Nepal in Dec 1976. He received his B. Tech. degree from Aligarh Muslim University, India in 2000 and M. Tech degree from Indian Institute of Technology, Kanpur, India in 2002, all in electrical engineering.

From 2002 to 2005 he worked as engineer with $\mathrm{ABB}$ Ltd (BU: HVDC and FACTS), India. In 2005 he joined Honeywell Technology Solutions (HTS), Bangalore, India. Since 2008, he is on sabbatical leave from HTS to pursue his Ph.D. at Aalborg University, Denmark. His research interests are in Power system analysis and simulation, HVDC and FACTS and wind power technology.

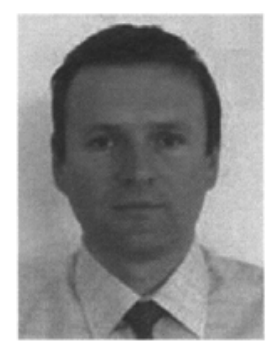

Remus Teodorescu received the Dipl.Ing. degree in electrical engineering from Polytechnical University of Bucharest, Romania in 1989, and $\mathrm{PhD}$. degree in power electronics from University of Galati, Romania, in 1994. In 1998, he joined Aalborg University, Department of Energy Technology, power electronics section where he currently works as full professor. $\mathrm{He}$ is the co-recipient of the Technical Committee Prize Paper Awards at IEEE 1AS Annual Meeting 1998, and Third-ABB Prize Paper Award at IEEE Optim 2002. He is a Senior Member of IEEE, Associate Editor for IEEE Power Electronics Letters and chair of IEEE Danish joint IES/PELS/IAS chapter. His areas of interests are: design and control of power converters used in renewable energy systems, distributed generation mainly wind power and photo-voltaics, computer simulations, digital control implementation.

Remus Teodorescu is the founder and coordinator of the Green Power Laboratory at Aalborg University focusing on the development and testing of grid converters for renewable energy systems and the coordinator of the Vestas Power Program. 


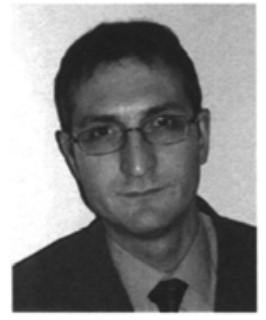

Pedro Rodriguez (S'99-M'04) received the M.S. and $\mathrm{Ph} . \mathrm{D}$. degrees in electrical engineering from the Technical University of Catalonia (UPC), Barcelona, Spain, in 1994 and 2004, respectively. In 1990, he joined the faculty of UPC as an Assistant Professor, where he is currently an Associate Professor. In 2005, he was a visiting researcher in the Center for Power Electronics Systems, Virginia Tech, USA. In 2006 and 2007, he was a Post-doc researcher in the Institute of Energy Technology, Aalborg University (AAU), Denmark, where he lectures $\mathrm{PhD}$. courses from 2006. He is now the Head of the Research Group on Renewable Electrical Energy Systems at the UPC and co-Supervisor of the Vestas Power Programme in partnership collaboration with the AAU. He has coauthored about 100 papers in technical journals and conferences. He is the holder of four patents. His research interest is focused on applying power electronics to distributed energy systems and power quality.

Dr. Rodriguez is a Member of the IEEE Power Electronics, IEEE Industry Application, and IEEE Industrial Electronics Societies. In this last society he has been active organizing several special sessions in conferences on the control of distributed energy systems based on renewable energies and presenting several tutorials. Currently, he is a member of the IEEE IES Technical Committee on Renewable Energy Systems and the chair of the IEEE Industrial Electronics Student Forum

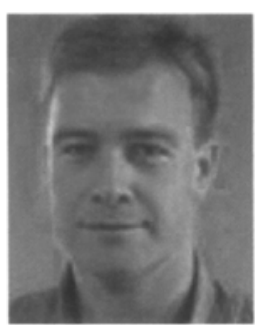

Philip Carne Kjaer received the M.Sc. degree in electrical engineering from Aalborg University, Aalborg, Denmark, in 1993, and the Ph.D. degree from the University of Glasgow, Glasgow, U.K., in 1997. From 1993 to 1998 , he was a Research Assistant at the University of Glasgow, working with advanced control of switched reluctance machines and drives. From 1998 to 2003, he was with ABB Corporate Research, Vasteras, Sweden, where, as a Development Engineer, he worked on servo-motor-based high-voltage circuit breaker drives, factory testing of synchronous machines, power converters for HVDC power transmission, and multi-megawatt variable-speed drives. Beginning in 2000, he also functioned as Deputy Department Manager and, most recently, as Group Manager for a team of 18 scientists. In October 2003, he joined Vestas Wind Systems, Arhus, Denmark, where he currently holds the position as Chief Specialist for power plants. He is the holder of four patents and has authored over 40 journal and conference publications. His research covers control and application of electrical machines and power electronic converters. Dr. Kjaer is a Chartered Engineer in the U.K., a Member of the Institution of Electrical Engineers, U.K., and the recipient of the 2004 Richard M. Bass Outstanding Young Power Electronics Engineer Award. 